\title{
The effects of resveratrol on hepatic oxidative stress in metabolic syndrome model induced by high fructose diet
}

\author{
Yilmaz Demirtas $\mathrm{C}^{1}$, Bircan FS ${ }^{2}$, Pasaoglu $\mathrm{OT}^{3}$, Turkozkan $\mathrm{N}^{1}$ \\ Department of Biochemistry, Faculty of Medicine, Gazi University, Ankara, Turkey. \\ fsbircan@yahoo.com
}

\begin{abstract}
BACKGROUND: The purpose of this study was to evaluate probable protective effects of resveratrol treatment on hepatic oxidative events in a rat model of metabolic syndrome (MetS).

METHODS: Thirty-two male adult rats were randomly divided into 4 groups: control, fructose, resveratrol, and fructose plus resveratrol. To induce MetS, fructose solution (20\% in drinking water) was used. Resveratrol (10 $\mathrm{mg} / \mathrm{kg} / \mathrm{day}$ ) was given by oral gavage. All treatments were given for 8 weeks. Serum lipid profile, glucose and insulin levels, liver total oxidant status (TOS) levels and paraoxonase (PON), glutathione peroxidase (GPx), superoxide dismutase (SOD) and catalase (CAT) activities were analyzed.

RESULTS: Fructose-fed rats displayed statistically significant increases in TOS levels, and decreases in PON activity compared to the control group. Resveratrol treatment moderately prevented the decrease in liver PON activity caused by fructose. On the other hand, resveratrol, alone or in combination with fructose, did not change the TOS levels when compared to the fructose group. The SOD and CAT activities in all groups did not change. CONCLUSION: In this experimental design, high-fructose consumption led to elevated TOS levels and low PON activities. The resveratrol therapy shown beneficial effects on PON activity. However, it was found to behave like a prooxidant when administered together with fructose and alone in some parameters. Our results can inspire the development of new clinical therapy in patients with MetS (Tab. 2, Ref. 34). Text in PDF www.elis.sk. KEY WORDS: resveratrol, metabolic syndrome, fructose, oxidative stress, liver.
\end{abstract}

\section{Introduction}

In metabolic syndrome (MetS), abdominal obesity, impaired fasting glucose, hypertension and hyperlipidaemia are combined findings. Elevated oxidative stress has been reported to play a crucial role in the pathogenesis of MetS, just as in many cardiometabolic diseases, and defined oxidative stress as a novel important ingredient of MetS $(1,2)$. Especially, the impaired balance between the prooxidant/antioxidant systems results in mild inflammation, endothelial dysfunction and insulin resistance. The defence mechanisms of the body against oxidative stress are complex and involve cellular and extracellular antioxidant systems, which are regulated at multiple levels by several antioxidant enzymes such as: glutathione peroxidase (GPx), superoxide dismutase (SOD), catalase (CAT) and paraoxonase (PON) (3). PON is a glycoprotein synthesized principally by the liver and associ-

${ }^{1}$ Department of Biochemistry, Faculty of Medicine, Gazi University, Ankara, Turkey, ${ }^{2}$ Department of Biology, Faculty of Science, Gazi University, Ankara, Turkey, and ${ }^{3}$ Faculty of Health Sciences, Gazi University, Ankara, Turkey

Address for correspondence: F.S. Bircan, PhD, Department of Biology, Faculty of Science, Gazi University, 06500, Teknikokullar, Ankara, Turkey. Phone: +90.312 .2021217$

Acknowledgement: This study was supported by Gazi University, Department of Scientific Research Projects Unit (Project Number: 01/2010-17). ated with HDL. It protects LDL from oxidation. Decline in PON activity in humans and experimental animals is associated with the formation of atherosclerosis and insulin resistance and rising in oxidative stress $(4,5)$.

Resveratrol, is called 3,5,4'-trihydroxystilbene, and is abundantly located in grapes, peanuts, other oilseeds, and blueberries. Resveratrol is a phytoalexin, and fungal infection, UV exposure or loss of water is expressed in such cases (6). Resveratrol has become an interesting molecule in early 1990's after its first discovery in wine and because of wine's positive cardiovascular effects. Many studies revealed its potentially beneficial effects in MetS treatment. These effects include but are not limited to antioxidant and anti-inflammatory effects $(7,8)$, maintenance of lipoprotein metabolism (9), vasodilatation (10), improvement of insulin sensitivity by lowering blood insulin and glucose levels (11). The mechanisms underlying the beneficial effects of resveratrol are not totally elucidated, but have been related mainly to its antioxidant activity (12). Resveratrol increases the antioxidant capacity by stimulating different antioxidant enzymes, but it is also made of a natural antioxidant with an effective free radical scavenger. The antioxidant activity of resveratrol is associated with the molecular structure. Resveratrol, due to the hydroxylated structure that can transfer by stabilizing the reactive species, $\mathrm{H}+$ atoms with radical derivatives, can stop the oxidative cascade (13).

In the present study, we aimed to investigate the effect of resveratrol on hepatic oxidative stress and the antioxidative system in a 
MetS model. In this direction, we measured TOS levels and PON, SOD, GPx and CAT activities in the livers of fructose-fed rats.

\section{Materials and methods}

\section{Chemicals}

Trans-resveratrol ( $\geq 99 \%)$ was purchased from Cayman Chemical (Spi-Bio, Montigny le Bretonneux, France). D-Fructose ( $\geq 99 \%$ ) was purchased from Sigma-Aldrich (St. Louis MO, USA). All other chemicals used were of the highest analytical grade, and purchased from Merck or Sigma-Aldrich.

\section{Animals and experimental design}

For this study, permission was obtained from the Animal Experimentation Ethics Committee of Gazi University (G.Ü.ET-10.037). Thirty-two male Sprague-Dawley rats $(225 \pm 10 \mathrm{~g})$ were obtained from Laboratory Animal Husbandry and Experimental Research Centre at Gazi University. The rats were housed at $20-24^{\circ} \mathrm{C}$ with a 12-h light/dark cycle and were provided with standard rat chow and fresh drinking water that was freely available.

The rats were randomly assigned to four groups of eight rats per group: 1) Control group: The rats in this group were fed a standard rodent chow and tap water; 2) Fructose group: The rats in this group were fed a standard rodent chow and tap water supplemented with $20 \%$ fructose (14); 3) Resveratrol group: The rats in this group were fed a standard rodent diet and tap water, and resveratrol administered at the dose of $10 \mathrm{mg} / \mathrm{kg}$ body weight/day by oral gavage (15). Resveratrol solution was prepared freshly every day; 4) Fructose plus resveratrol group: Rats in this group received a standard rodent diet and tap water supplemented with $20 \%$ fructose, and resveratrol administered at the dose of $10 \mathrm{mg} /$ $\mathrm{kg}$ body weight/day by oral gavage.

Resveratrol was prepared in $0.1 \%$ ethanol. Accordingly, the control and fructose groups were treated with $0.1 \%$ ethanol to nullify the effects of ethanol. The experiment was carried out for 8 weeks and at the end of this duration, fasted rats were anaesthetized with ketamine $(30 \mathrm{mg} / \mathrm{kg} \mathrm{bw})$ and xylazine $(6 \mathrm{mg} / \mathrm{kg} \mathrm{bw})$.
Blood was collected into tubes, and then serum was separated by centrifugation. Liver tissues were washed in a cold solution of 0.9 $\%$ sodium chloride, and dried. Sera and liver samples were stored at $-80^{\circ} \mathrm{C}$ until analysis.

\section{Systolic blood pressure, body weight, fluid intake}

SBP was measured by the tail-cuff method at the beginning of the study, at the end of week 4, and at the end of week 8 . At least seven measurements were made in every session and the mean of the lowest three values within $5 \mathrm{mmHg}$ was taken as the SBP value. Body weights were recorded weekly and fluid intake of all above groups was measured daily.

\section{Serum analysis}

Serum glucose, triglyceride, VLDL-cholesterol levels were measured by enzymatic methods using autoanalyzers. Serum insulin level was detected by using a commercially available ELISA kit (Millipore, MA, USA). Insulin resistance was evaluated by the Homeostasis Model Assessment index (HOMA-IR) using the formula: $\operatorname{insulin}(\mathrm{mU} / \mathrm{L}) \times$ glucose $(\mathrm{mmol} / \mathrm{L})] / 22.5$.

\section{TOS levels measurement}

The TOS levels of liver tissues were determined using a new automated measurement method (RelAssay Diagnostics, Turkey). The parameter is calibrated with hydrogen peroxide $\left(\mathrm{H}_{2} \mathrm{O}_{2}\right)$ and the results are expressed in terms of micromolar $\mathrm{H}_{2} \mathrm{O}_{2}$ equivalents per gram tissue ( $\mu \mathrm{mol} \mathrm{H}_{2} \mathrm{O}_{2}$ equiv./g tissue).

\section{Enzyme activities measurement}

PON activity was measured using a new measurement method developed by Erel (16). The PON activity is expressed as U/g tissue. GPx activities were assayed in a 96-well microliter plate using commercially available colorimetric kit (Cayman Chemical, Spi-Bio, Montigny le Bretonneux, France). Amounts were expressed as IU/g tissue. SOD activity was assayed according to the method of Yi-Sun et al (17). The results of the activity were expressed as IU/g tissue. CAT activity was measured by spectro-

Tab. 1. SBP and serum values related to MetS at 8 weeks.

\begin{tabular}{|c|c|c|c|c|c|c|}
\hline & $\begin{array}{c}\mathrm{SBP} \\
(\mathrm{mmHg})\end{array}$ & $\begin{array}{c}\text { Triacylglyceroles } \\
(\mathrm{mg} / \mathrm{dl})\end{array}$ & $\begin{array}{l}\text { VLDL-Cholesterol } \\
(\mathrm{mg} / \mathrm{dl})\end{array}$ & $\begin{array}{c}\text { Glucose } \\
(\mathrm{mmol} / \mathrm{L})\end{array}$ & $\begin{array}{l}\text { Insulin } \\
(\mathrm{mU} / \mathrm{L})\end{array}$ & HOMA-IR \\
\hline Control & $125 \pm 1.2$ & $36.00 \pm 8.07$ & $8.00 \pm 2.39$ & $12.299 \pm 2.19$ & $4.799 \pm 1.809$ & $2.676 \pm 1.112$ \\
\hline Fructose & $160 \pm 1.4^{\mathrm{a}}$ & $93.75 \pm 15.85^{\mathrm{a}}$ & $18.75 \pm 3.24^{\mathrm{a}}$ & $13.195 \pm 1.54$ & $28.210 \pm 6.029^{\mathrm{a}}$ & $16.716 \pm 4.893^{a}$ \\
\hline Resveratrol & $124 \pm 1.1^{\mathrm{b}}$ & $55.12 \pm 7.49^{\mathrm{a}, \mathrm{b}}$ & $11.00 \pm 2.27^{\mathrm{a}, \mathrm{b}}$ & $14.236 \pm 1.725$ & $8.403 \pm 1.238^{\mathrm{a}, \mathrm{b}}$ & $5.342 \pm 1.172^{\mathrm{a}, \mathrm{b}}$ \\
\hline $\mathrm{Fr}+\mathrm{Rsv}$ & $127 \pm 2.3^{b}$ & $143.62 \pm 27.68^{\mathrm{a}, \mathrm{b}, \mathrm{c}}$ & $25.00 \pm 3.02^{\mathrm{a}, \mathrm{b}, \mathrm{c}}$ & $11.294 \pm 2.338^{c}$ & $34.266 \pm 7.334^{\mathrm{a}, \mathrm{c}}$ & $17.021 \pm 4.481^{\mathrm{a}, \mathrm{c}}$ \\
\hline
\end{tabular}

Shown are the means $\pm \mathrm{SD}\left(\mathrm{n}=8\right.$ per group). ${ }^{\mathrm{a}} \mathrm{p}<0.05 \mathrm{vs}$ control; ${ }^{\mathrm{b}} \mathrm{p}<0.05 \mathrm{vs}$ fructose; ${ }^{\mathrm{c}} \mathrm{p}<0.05 v s$ resveratrol group.

Tab. 2. Liver TOS levels and antioxidant enzyme activities.

\begin{tabular}{|c|c|c|c|c|c|}
\hline & $\begin{array}{c}\text { TOS } \\
\left(\mu \mathrm{mol} \mathrm{H} \mathrm{O}_{2} \text { Equiv/g tissue }\right)\end{array}$ & $\begin{array}{c}\text { PON } \\
\text { (U/g tissue) }\end{array}$ & $\begin{array}{c}\mathrm{GPx} \\
(\mathrm{nmol} / \mathrm{min} / \mathrm{g} \text { tissue })\end{array}$ & $\begin{array}{c}\text { SOD } \\
\text { (U/g tissue) }\end{array}$ & $\begin{array}{c}\text { CAT } \\
\text { (U/g protein) }\end{array}$ \\
\hline Control & $38.5 \pm 8.9$ & $329.2 \pm 57$ & $1.9 \pm 0.69$ & $83 \pm 1$ & $101 \pm 14$ \\
\hline Fructose & $75.8 \pm 13.8^{a}$ & $184.3 \pm 43^{\mathrm{a}}$ & $2.5 \pm 0.92$ & $85 \pm 1.7$ & $98 \pm 5$ \\
\hline Resveratrol & $80 \pm 20.8^{\mathrm{a}}$ & $211.7 \pm 25.7^{\mathrm{a}}$ & $2.0 \pm 0.72$ & $77 \pm 2.5$ & $100 \pm 10$ \\
\hline $\mathrm{Fr}+\mathrm{Rsv}$ & $100.8 \pm 22.9^{\mathrm{a}}$ & $247.6 \pm 24.5^{\mathrm{a}}$ & $1.8 \pm 0.42$ & $83 \pm 5$ & $105 \pm 12$ \\
\hline
\end{tabular}

Shown are the means \pm SD ( $n=8$ per group). ${ }^{a} \mathrm{p}<0.05$ vs control $;{ }^{b} \mathrm{p}<0.05$ vs fructose; ${ }^{\mathrm{c}} \mathrm{p}<0.05$ vs resveratrol group. 
photometric analysis of the rate of $\mathrm{H}_{2} \mathrm{O}_{2}$ decomposition at $240 \mathrm{~nm}$; enzyme activity was expressed as IU/g protein (18). Tissue total protein concentrations were evaluated by the BCA protein assay kit (Thermo Fisher Scientific, Rockford, IL, USA).

\section{Statistical analysis}

Statistical analysis was conducted using SPSS 16.0 software. All values were expressed as the mean \pm SD. Kruskal-Wallis analysis of variance and Bonferroni's multiple comparison test were made. Probability values less than 0.05 were accepted as significant.

\section{Results}

Fructose feeding caused a significant increase in SBP, serum triglycerides, VLDL-cholesterol and insulin levels and it induced insulin resistance. Table 1 summarizes SBP and the changes in a number of blood analytes used clinically to assess the MetS in the four groups of animals examined.

Comparison of the oxidative stress parameters between the fructose and control groups revealed a statistically significant increase in the TOS levels in the fructose group. By contrast, resveratrol, supplied alone or in combination with fructose, did not change the TOS levels when compared to the fructose group (Tab. 2).

The PON activities were statistically significantly lower in the fructose group than in the control group. Resveratrol supplementation, alone or in combination with fructose, increased the PON activities compared to the fructose group. However, this increase was not statistically significant (Tab. 2). As shown in Table 2, the GPx activities significantly raised in resveratrol group compared to all other groups. The SOD and CAT activities were remained unchanged in all groups compared to the control group.

\section{Discussion}

MetS is associated with insulin resistance, hyperinsulinemia, dyslipidaemia and hypertension. It has been reported that there is a close relationship between elevated fructose intake and the incidence of MetS (19). Many investigations have shown that the fructose-fed rat model causes an insulin resistance syndrome with a much like metabolic profile to the human situation (20). Nonetheless, the reported metabolic alterations observed in fructose-fed rats are quite divergent among different studies. This divergence may reflect differences in experiment designs, which could include the strain of rat used, the amount and administration route of fructose, the age of the animals and the fructose administration term (14). In present study, we used Sprague-Dawley male adult rats and fructose administration was carried by providing $20 \% \mathrm{D}$-fructose in drinking water for 8 weeks. At the end of eight weeks, hypertension, hyperinsulinemia, insulin resistance and hypertriglyceridemia were determined in the fructose-fed rats when compared to the control group. MetS model was successfully created (Tab. 1).

Fructose stimulates fat deposition in the liver and simultaneously increases fat synthesis and prevents fat oxidation, leads to hepatic steatosis and non-alcoholic fatty liver diseases. Besides, high fructose intake induces oxidative stress, essentially through the deterioration of the antioxidant defence system. The induction of MetS is associated with upright oxidative stress and activation of inflammatory cytokines (21). In a recent study, fructose administration increased TOS levels while PON activities were reduced in liver tissues. However, it did not cause any change in GPx, CAT and SOD activities. In accordance with our results, studies conducted by Sripradha et al. (22) and Maithili Karpaga Selvi et al (23) showed that liver TOS levels showed a significant increase in fructose-fed rats. The researchers suggested that there was a close relationship between increased liver TOS levels and increased ROS production from accumulated fat, leading to an increased oxidative stress in blood, affecting other organs including the liver. Similarly, Ackerman et al (24) showed that dietary fructose for 6 weeks reduced hepatic PON activity ( $-46 \%$ ). In addition, there are various studies investigating the effect of fructose diet on liver antioxidant enzyme activities. However, the results of these studies probably differ according to the manner and duration of administration of the fructose diet. For instance, Bagul et al (25) showed that fructose-enriched diet (65\% for 8 weeks) significantly reduced liver SOD activity while not altering CAT activity. In contrast, Ilhan et al. (26) supplemented $10 \%$ fructose diet (in drinking water) during 5 weeks to the rats and reported that fructose did not change liver SOD activity.

Resveratrol, which has antioxidant and anti-inflammatory properties, is a natural phytoalexin. Major dietary sources include grapes, peanuts, berries, soy beans and pomegranate. Nowadays, many beneficial effects of resveratrol are described. However, the results obtained were in much higher doses than those that reach people through the normal diet. Therefore, for the potential effects of resveratrol, pharmaceutical use is required in addition to the diet. In recent years, resveratrol has been synthesized by chemical or biotechnological means, and nutritional supplements are produced from Polygonum cuspidatum. Through these supplements, as encapsulated in 20-500 mg doses, resveratrol (3-83 times higher than the level of the log diet) can be supplied $(27,28)$.

In the present study, resveratrol was administered in addition to the standard rat diet and fructose diet at a daily dose of $10 \mathrm{mg} /$ $\mathrm{kg}$ for 8 weeks. We found that resveratrol treatment did not alter SOD, GPx and CAT activities in the resveratrol and fructose plus resveratrol groups. Unlike our findings, Bagul et al (25) observed that resveratrol treatment increased hepatic CAT and SOD activities in fructose-fed rats. In mice steatosis model, resveratrol supplementation ( 2 and $4 \mathrm{~g} / \mathrm{kg} /$ day) has been reported to increase liver GPx activity (29). On the other hand, we determined that resveratrol therapy prevented the decrease in liver PON activity caused by fructose, but the PON activity did not reach the level of the control group. In literature, no study was found that examined the effects of resveratrol on PON activity in MetS model. Ahn et al (30) reported that the hepatic mRNA expression of PON1 was significantly reduced by the atherogenic diet and the resveratrol treatment for 8 weeks attenuated this decrease in mice. In a different study of human hepatocyte cultures and $\mathrm{HuH} 7$ cells, resveratrol was shown to increase PON1 gene expression. This effect of 
resveratrol appeared to be dependent upon the activation of the Ah receptor and to effect on specific PON1's promoter region (31). As it is in those studies, the positive effect of resveratrol on liver PON activity may be related to the regulation of gene expression in our animal model.

In our study, no protective effect of resveratrol on TOS levels has been observed. Moreover, the resveratrol and fructose plus resveratrol groups' TOS levels were found to be the same as those of the fructose group. Our results, in this dose $(10 \mathrm{mg} /$ $\mathrm{kg}$ /day) and duration (8 weeks), suggest that resveratrol is an effective prooxidant. In literature, a study confirming our results in terms of this parameter was not found. However, in addition to antioxidant effects, there are also studies, in which prooxidant activity of resveratrol is determined, depending on its concentration and cell type. Resveratrol is metabolized by the peroxidase enzyme as other polyphenols, and the formed phenoxyl radicals can catalyse oxidative reactions in the presence of copper ions (32-34). In our experimental conditions, the effect of resveratrol mentioned above may have emerged.

\section{Conclusion}

In this study, hypertension, hypertriglyceridemia, hyperinsulinemia and insulin resistance results were obtained in rats given high fructose diet for 8 weeks and the MetS model was successfully applied. The MetS pattern can be generated by $20 \%$ fructose application for 8 weeks, but this model may not be sufficient for the complications of oxidative stress in MetS. In the following study, the duration of fructose exposure may be increased to examine long-term consumption effects, such as in humans. In addition, it may provide more descriptive information about the resveratrol test at different doses. Our results can inspire the development of new clinical therapy in patients with MetS.

\section{References}

1. Gregorio BM, De Souza DB, de Morais Nascimento FA, Pereira LM, Fernandes-Santos C. The potential role of antioxidants in metabolic syndrome. Curr Pharm Des 2016; 22 (7): 859-869.

2. Hopps E, Noto D, Caimi G, Averna MR. A novel component of the metabolic syndrome: the oxidative stress. Nutr Met Cardiovasc Dis 2010; 20: 72-77.

3. Elnakish MT, Hassanain HH, Janssen PM, Angelos MG, Khan M. Emerging role of oxidative stress in metabolic syndrome and cardiovascular diseases: important role of Rac/NADPH oxidase. J Pathol 2013; 231: $290-300$.

4. Fülöp P, Harangi M, Seres I, Paragh G. Paraoxonase-1 and adipokines: potential links between obesity and atherosclerosis. Chem Biol Interact 2016; 259 (Pt B): 388-393.

5. Kulka M. A review of paraoxonase 1 properties and diagnostic applications. Pol J Vet Sci 2016; 19 (1): 225-232.

6. Hasan M, Bae H. An overview of stress-induced resveratrol synthesis in grapes: perspectives for resveratrol-enriched grape products. Molecules 2017; 22 (2): E294.
7. Cai YJ, Fang JG, Ma LP, Yang L, Liu ZL. Inhibition of free radicalinduced peroxidation of rat liver microsomes by resveratrol and its analogues. Biochim Biophys Acta 2003; 1637: 31-38.

8. Donnelly LE, Newton R, Kennedy GE, et al. Anti-inflammatory effects of resveratrol in lung epithelial cells: molecular mechanisms. Am J Physiol 2001; 287: L774-L783.

9. Soleas GJ, Diamandis EP, Goldberg DM. Resveratrol: a molecule whose time has come? and gone? Clin Biochem 1997; 30: 91-113.

10. Chen CK, Pace-Asciak CR. Vasorelaxing activity of resveratrol and quercetin in isolated rat aorta. Gen Pharmacol 1996; 27: 363-366.

11. Szkudelski T, Szkudelska K. Resveratrol and diabetes: from animal to human studies. Biochim Biophys Acta 2015; 1852 (6): 1145-1154.

12. Schmatz R, Perreira LB, Stefanello N, et al. Effects of resveratrol on biomarkers of oxidative stress and on the activity of delta aminolevulinic acid dehydratase in liver and kidney of streptozotocin-induced diabetic rats. Biochimie 2012; 94 (2): 374-383.

13. Pandey KB, Rizvi SI. Anti-oxidative action of resveratrol: implications for human health. Arabian J Chem 2011; 4: 293-298.

14. de Moura RF, Ribeiro C, de Oliveira JA, Stevanato E, de Mello MA. Metabolic syndrome signs in Wistar rats submitted to different highfructose ingestion protocols. Br J Nutr 2009; 101: 1178-1184.

15. Miatello R, Vazguez M, Renna N, Cruzado M, Zumino AP, Risler N. Chronic administration of resveratrol prevent biochemical cardiovascular changes in fructose-fed rats. Am J Hypertension 2005; 18 (6): 864-870.

16. Erel O. A new automated colorimetric method for measuring total oxidant status. Clin Biochem 2005; 38 (12): 1103-1111.

17. Yi-Sun S, Oberly LW, Li Y. A simple method for clinical assay of superoxide dismutase. Clin Chem 1988; 34: 497-500.

18. Aebi H. Catalase, In: H.U.Bergmeyer, (Ed): Methods of Enzymatic Analysis, Academic Press, New York and London, 1974; 673-677.

19. Khitan Z, Kim DH. Fructose: a key factor in the development of metabolic syndrome and hypertension. J Nutr Metab 2013; 2013: 682673.

20. Johnson RJ, Segal MS, Sautin Y, et al. Potential role of sugar (fructose) in the epidemic of hypertension, obesity and the metabolic syndrome, diabetes, kidney disease, and cardiovascular disease. Am J Clin Nutr 2007; 86: 899-906.

21. Zhang DM, Jiao RQ, Kong LD. High dietary fructose: direct or indirect dangerous factors disturbing tissue and organ functions. Nutrients 2017; 9 (4): E335.

22. Sripradha R, Sridhar MG, Maithili Karpaga Selvi N. Hydroxycitric acid ameliorates high-fructose-induced redox imbalance and activation of stress sensitive kinases in male Wistar rats. J Basic Clin Physiol Pharmacol 2016; 27 (4): 349-356.

23. Maithili Karpaga Selvi N, Sridhar MG, Swaminathan RP, Sripradha R. Curcumin attenuates oxidative stress and activation of redoxsensitive kinases in high fructose- and high-fat-fed male Wistar rats. Sci Pharm 2014; 83 (1): 159-175.

24. Ackerman Z, Oron-Herman M, Pappo O, et al. Hepatic effects of rosiglitazone in rats with the metabolic syndrome. Basic Clin Pharmacol Toxicol 2010; 107 (2): 663-668.

25. Bagul PK, Middela H, Matapally $S$, et al. Attenuation of insulin resistance, metabolic syndrome and hepatic oxidative stress by resveratrol in fructose-fed rats. Pharmacol Res 2012; 66 (3): 260-268. 
$36-40$

26. İlhan N, Güngör H, İlhan AŞ. Effects of resveratrol on oxidant and antioxidant systems in model of rat metabolic syndrome. Turk J Biochem 2014; 39 (4): 449-454.

27. Borriello A, Cucciolla F, Ragione D, Galletti P. Dietary polyphenols: focus on resveratrol, a promising agent in the prevention of cardiovascular diseases and control of glucose homeostasis. Nutr Metab Cardiovasc Dis 2010; 20 (8): 618-625.

28. Brown L, Kroon PA, Das DK, et al. The biological responses to resveratrol and other polyphenols from alcoholic beverages. Alcohol Clin Exp Res 2009; 33 (9): 1513-1523.

29. Zhu W, Chen S, Li Z, et al. Effects and mechanisms of resveratrol on the amelioration of oxidative stress and hepatic steatosis in KKAy mice. Nutr Metab (Lond) 2014; 11: 35.

30. Ahn J, Cho I, Kim S, Kwon D, Ha T. Dietary resveratrol alters lipid metabolism-related gene expression of mice on an atherogenic diet. J Hepatol 2008; 49 (6): 1019-1028.
31. Costa LG, Giordano G, Furlong CE. Pharmacological and dietary modulators of paraoxonase 1 (PON1) activity and expression: the hunt goes on. Biochem Pharmacol 2011; 81 (3): 337-344.

32. Fujimoto A, Sakanashi Y, Matsui H, et al. Cytometric analysis of cytotoxicity of polyphenols and related phenolics to rat thymocytes: potent cytotoxicity of resveratrol to normal cells. Basic Clin Pharmacol Toxicol 2009; 104 (6): 455-462.

33. Hassan-Khabbar S, Cottart CH, Wendum D, et al. Postischemic treatment by trans-resveratrol in rat liver ischemia-reperfusion: a possible strategy in liver surgery. Liver Transpl 2008; 14 (4): 451-459.

34. Takahashi S, Uchiyama T, Toda K. Differential effect of resveratrol on nitric oxide production in endothelial $\mathrm{f}-2$ cells. Biol Pharm Bull 2009; 32 (11): 1840-1843.
Received July 7, 2017. Accepted August 25, 2017. 